\title{
New gene construction strategy in T-DNA vector to enhance expression level of sweet potato sporamin and insect resistance in transgenic Brassica oleracea
}

\author{
Huai-Ju Chen ${ }^{\text {a }}$, Shu-Jen Wang ${ }^{\mathrm{b}}$, Chien-Cheng Chen ${ }^{\mathrm{a}}$, Kai-Wun Yeh ${ }^{\mathrm{a}, *}$ \\ ${ }^{a}$ Graduate Institute of Plant Biology, College of Life Science, National Taiwan University, Taipei 106, Taiwan \\ ${ }^{\mathrm{b}}$ Department of Agronomy, College of Bioresource and Agriculture, National Taiwan University, Taipei 106, Taiwan \\ Received 15 February 2006; received in revised form 1 April 2006; accepted 16 April 2006 \\ Available online 5 May 2006
}

\begin{abstract}
Sporamin, an abundant storage protein in tuberous roots of sweet potato, possesses strong inhibitory activity against trypsin and pest-resistance. To promote consistent high-level expression of sporamin and insect resistance in transgenic Brassica plants, a wound-responsive sporamin promoter (Pspoa) alone or combined with matrix-attached-region-like DNA segment (spoMAR) were constructed for driving sporamin cDNA. The results showed the transgenic plants containing Pspoa-drived sporamin and spoMAR displayed the highest level and low inter-transformant variability of sporamin expression, and the ability of insect resistance of transformants positively correlated with sporamin activity. Furthermore, expressions of Pspoa-drived sporamin especially combined with the spoaMAR retains high and steady levels in the $\mathrm{T}_{1}$ and $\mathrm{T}_{2}$ generations, in marked contrast to the variable expression patterns observed in CaMV35S promoter-driven transformants. This study evidently indicates that the Pspoa and spoaMAR would be very efficient for high transgene expression in plants and obtaining inherently stable transformants in consecutive progenies.
\end{abstract}

(C) 2006 Elsevier Ireland Ltd. All rights reserved.

Keywords: Brassica; Genetic variability; Matrix-attached region; Sporamin; Trypsin inhibitor

\section{Introduction}

Sporamin is a major storage protein accounted for over $80 \%$ of the total soluble protein in sweet potato tuberous roots first described by Maeshima et al. [1]. Spatial expression of sporamin has been shown to be mainly associated with tuberous roots and a very low amount in the stem, but not in leaves [2,3]. Systemic expressions, however, could be induced by wounding infliction and other stress-related chemicals [4,5]. Importantly, it has been demonstrated that sporamin is a strong trypsin inhibitor (TI) based on the in-gel activity analysis of recombinant proteins on SDS-PAGE [6].

During the past years, sporamin gene has been introduced to tobacco and cauliflower plants via Agrobacterium tumefaciensmediated transformation. It showed that the ectopic overexpression of sporamin driven by cauliflower mosaic virus $35 \mathrm{~S}$

\footnotetext{
* Corresponding author. Tel.: +8862 33662536; fax: +886223622703. E-mail address: ykwbppp@ntu.edu.tw (K.-W. Yeh).
}

(CaMV35S) promoter could confer an effective insect/ nematode-resistance on transgenic plants [7-9]. The survey on transgenic plant lines indicated the magnitude of nematode resistance of transgenic plants was closely correlated with the expression level of sporamin transgene [9]. However, sporamin expression level in most transgenic tobacco and cauliflower lines gradually declined during serial propagation in tissue culture and in successive generations. It was suggested that this occurrence of gene silence was happening in sporamin transformation driven by CaMV35S promoter. For agricultural application of genetic modified organism technology, highlevel and stable expression of transgene under field conditions is an essential requirement. In order to develop functional and efficient transgenic crops as an integral part of agricultural systems, we have considered several factors to improve sporamin-expression in transgenic population. The factors, such as promoter strength, enhancer DNA segment, and intron segment are thought to influence transgene expression level [10-12]. Promoters, for instance, not only affect transgene expression but affect the magnitude of expression variability 
among individual transformants also [13]. It has been reported that the widely used CaMV35S promoter yields a bimodal expression pattern with high expression levels in a limited number of transgenic plants and very low expression levels in the majority of the transformants $[13,14]$.

In continuation with the previous works, we have taken up this study to find out a method to elevate the gene expression level and insect-resistant efficiency of sweet potato sporamin in transgenic plants. To achieve this, two major factors, i.e. woundinducible sporamin promoter, Pspoa, and matrix attachment region (MAR)-like sequence of sporamin gene (spoaMAR) were incorporated into the improvement strategy. It has been shown that Pspoa exhibits high-level of regulatory activity, and efficiently and rapidly expressed in response to wounding in transgenic tobacco [5]. MAR is found in eukaryotic genome as non-transcriptional regions that attach to the proteinaceous matrix in the nucleus. It appears that they trigger the formation of chromatin loops and thereby shielding genes from chromosomal position effects [15]. MAR sequence located in the proximity of transgenes can affect expression level and variability [16,17]. In this report, the potential function of Pspoa and spoaMAR on increasing the sporamin expression for improving the insectresistance were demonstrated in transgenic Brassica.

\section{Materials and methods}

\subsection{Plant material}

The Brassica oleracea cv. alboglabra Boa2301 seeds kindly provided by Ming-Fong Seed Company in Taiwan were used as the transgene receptor.

\subsection{Vector constructs and bacterial strain}

Binary vector, pBI121, was used as backbone to generate transgenic constructs. For pP35S-sporamin construct, sporamin cDNA $(0.9 \mathrm{~kb})$ was subcloned at BamHI and SmaI site under the driving of CaMV35S (P35S) promoter. For pPspoasporamin construct, P35S promoter was replaced by $1.25 \mathrm{~kb}$ sporamin promoter (Pspoa) [5] at Pst I and Xba I site. For pPspoa-sporamin-spoaMAR, a $2.0 \mathrm{~kb}$ DNA fragment encompassing the full-length sporamin cDNA $(0.9 \mathrm{~kb})$ and the extension of $1.1 \mathrm{~kb} 3^{\prime}$ downstream DNA sequence was amplified from the genomic clone encoded a protein member of sporamin A family, gSPO-A [18]. This DNA fragment was subsequently subcloned to replace sporamin cDNA insert in pPspoa-sporamin construct. In the latter two vector constructs, sporamin gene was drove by its self-promoter region. In the third vector construct, sporamin cDNA was extended with its own downstream sequence. These three complete constructs were transformed to A. tumefaciens LBA4404 following the method described by Hofgen and Willmitzer [19].

\subsection{Plant regeneration system}

For gene transformation process, the plant regeneration protocol was prior established as the following protocol [20].
Seeds of B. oleracea were sterilized with $70 \%$ (v/v) ethanol containing 1-2 drops of tween-20 and $0.1 \%$ (w/v) mercuric chloride $\left(\mathrm{HgCl}_{2}\right)$, and then rinsed several times with sterilized distilled water. Following, the seeds were germinated on $1 / 2$ MS basal medium supplemented with $2 \%(\mathrm{v} / \mathrm{v})$ sucrose for 5 days. Hypocotyl segments were excised from five-day-old seedlings and cultured on callus-induction MS medium containing $1 \mathrm{mg} \mathrm{L}^{-1}$ picloram, $2 \mathrm{mg} \mathrm{L}^{-1} \mathrm{BA}, 2 \%$ (w/v) sucrose and $10 \mathrm{mg} \mathrm{L}^{-1}$ silver nitrate. Shoot buds were elongated on shoot-induction medium consisting of $0.3 \%$ (w/ v) hyponex, $100 \mathrm{mg} \mathrm{L}^{-1}$ myo-inositol, $1 \mathrm{mg} \mathrm{L}^{-1} \mathrm{NAA}$, $0.5 \mathrm{mg} \mathrm{L}^{-1}$ BA and 3\% (w/v) sucrose. After 8-12 weeks, shoots with 3-4 cm length were excised and cultured on rootinduction medium $\left(3 \mathrm{~g} \mathrm{~L}^{-1}\right.$ hyponex, $100 \mathrm{mg} \mathrm{L}^{-1}$ myoinositol, $1 \mathrm{mg} \mathrm{L}^{-1} \mathrm{NAA}$ and $2 \%$ (w/v) sucrose). All the media were gelled with $0.8 \%$ agar and cultures were incubated under white florescent light $\left(28 \mu \mathrm{mol} \mathrm{m} \mathrm{s}^{-2}\right)$ with $16 \mathrm{~h}-$ light/ $8 \mathrm{~h}$ dark photoperiod at $25{ }^{\circ} \mathrm{C}$.

\subsection{Gene transformation and plant growth condition}

The A. tumefaciens LBA4404 harboring the three respective sporamin gene constructs were used to transform hypocotyl explants. Single colony of Agrobacterium LBA4404 was transferred to liquid YEP medium with $50 \mathrm{mg} \mathrm{L}^{-1}$ kanamycin, $30 \mathrm{mg} \mathrm{L}^{-1}$ streptomycin, and incubated at $20{ }^{\circ} \mathrm{C}$ for 2 days. The bacteria was centrifuged and re-suspended in liquid MS medium supplemented with $50 \mu \mathrm{M}$ acetosyringone and incubated for further 4-6 h. For gene transformation, hypocotyl segments were infected with this Agrobacterium $\left(\mathrm{OD}_{600}=0.4\right.$ 0.5 ) for $8 \mathrm{~min}$, and then filter dried to remove the excesses of bacteria present on the surface of explants. The explants and bacteria were co-cultured in callus-induction medium for 2 days in dark. The co-cultivated explants were washed three to five times in steriled water for $10 \mathrm{~min}$ each, followed by washing in MS medium containing $500 \mathrm{mg} \mathrm{L}^{-1}$ carbenicillin for $45 \mathrm{~min}$. Then, explants were inoculated in shoot-induction medium with $500 \mathrm{mg} \mathrm{L}^{-1}$ carbenicillin for 2 weeks. In the subsequent subcultures, $50 \mathrm{mg} \mathrm{L}^{-1}$ of kanamycin were added to shoot-induction medium for transgenic plants selection. The selected shoots of transgenic and control clones were transferred to other medium for rooting before the plants were transferred to the greenhouse.

\subsection{Trypsin inhibitor activity assay}

Trypsin inhibitor activity of sporamin was both qualitatively and quantitatively analyzed. In qualitative assay, proteins were extracted from the transgenic leaves after 30 min for woundingtreatment. The extraction method and buffer were as the description of Yeh et al. [6]. The extract was centrifuged twice at $10,000 \times g$ for 15 min to remove pellet, and total protein was quantified following the method described by Bradford [21]. Crude protein extract (100 $\mu$ g per each sample) was separated on $15 \%$ SDS-PAGE, Then, the gel was subsequently treated as described by Yeh et al. [6]. In brief, the gel was immersed in trypsin solution, and then gently shaken in dark at room 
temperature with $N$-acetyl-D,L-phenylalanine- $\beta$-naphthyl ester (APNE) and $o$-dianisidine dye for $30 \mathrm{~min}$. After the procedure, sufficient $7.5 \%(\mathrm{v} / \mathrm{v})$ acetic acid was applied to stop the reaction.

In addition, the quantitative activity assay was performed following the method described by Yao et al. [22]. Protein extract of plant tissues was reacted with trypsin (1:1 molar ratio) at $37{ }^{\circ} \mathrm{C}$ for $10 \mathrm{~min}$, and then $N$-benzoyl-D,L-arginine- $\beta$ nitroanilide (BAPA) was added to a final concentration of $500 \mathrm{mg} \mathrm{L}^{-1}$ for further reaction for $30 \mathrm{~min}$. The optical density of the reaction mixture was then measured at $410 \mathrm{~nm}$. The TI activity, i.e. percentage inhibition of trypsin by sporamin, was calculated using the below equation:

TI activity $=\left[\frac{\left(T-T^{*}\right)}{T}\right] \times 100 \%$

where $T$ denotes the $\mathrm{OD}_{410}$ in the absence of sporamin, and $T^{*}$ is that in the presence of sporamin.

\subsection{Reverse transcriptase (RT)-PCR analysis}

For analysis of sporamin gene expression, total RNA of transgenic plants was extracted from the leaves harvested after wounding-treatment for $30 \mathrm{~min}$. Total RNA was isolated using Trizol reagent (Invitrogen, CA, USA). RT-PCR analysis was performed by OneStep RT-PCR Kit included Omniscript/
Sensiscript Reverse Transcriptases mix and HotStar Taq polymerase following the instruction (Qiagen, CA, USA).

\subsection{Insect bioassays}

Transgenic and control leaves of same size were randomly cut and placed in $9 \mathrm{~cm}$ petri dish which contained $2 \%(\mathrm{w} / \mathrm{v})$ agar. A filter paper was covered on it to retain proper moisture. Twenty early second instar larvae of maize cutworm (Helicoverpa armigera Hubner) were put in the petri dish to feed the leaves. The fresh leaf disc was supplied every $24 \mathrm{~h}$. The body weight and insect survival rate were measured after 4 day feeding test.

\section{Results}

\subsection{Generation of constructs for transgenic expression of sporamin in Brassica}

Three binary vector constructs, pP35S-sporamin, pPspoasporamin and pPspoa-sporamin-spoaMAR, were generated based on the backbone of pBI121 binary vector (Fig. 1). pP35Ssporamin construct played a role as control. Pspoa used in the second and third constructs was a $1.25 \mathrm{~kb}$ DNA fragment located at the upstream of sporamin cDNA, and employed as a promoter to drive sporamin cDNA (Fig. 1). The third construct

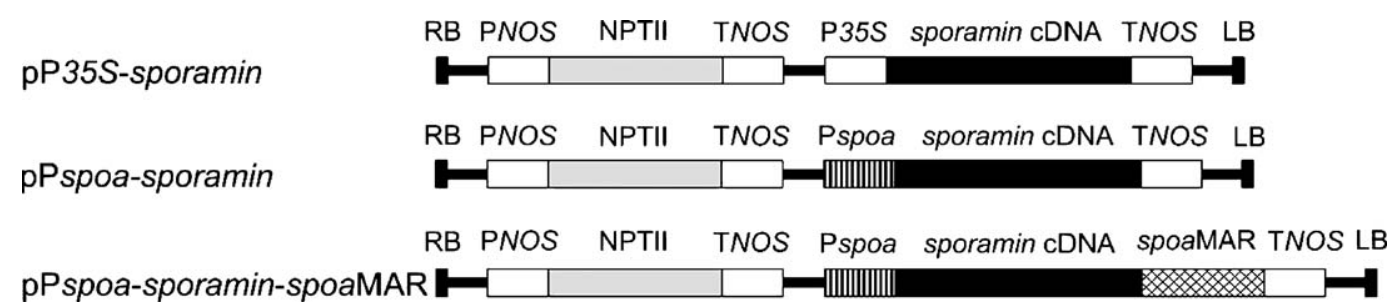

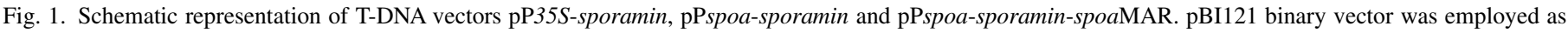

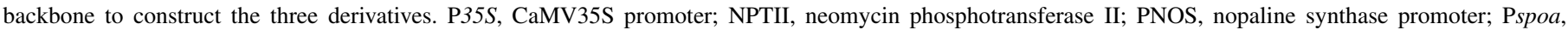

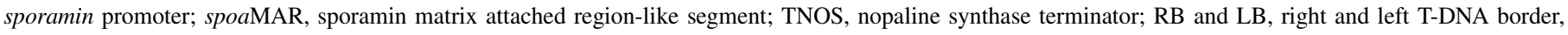
respectively.

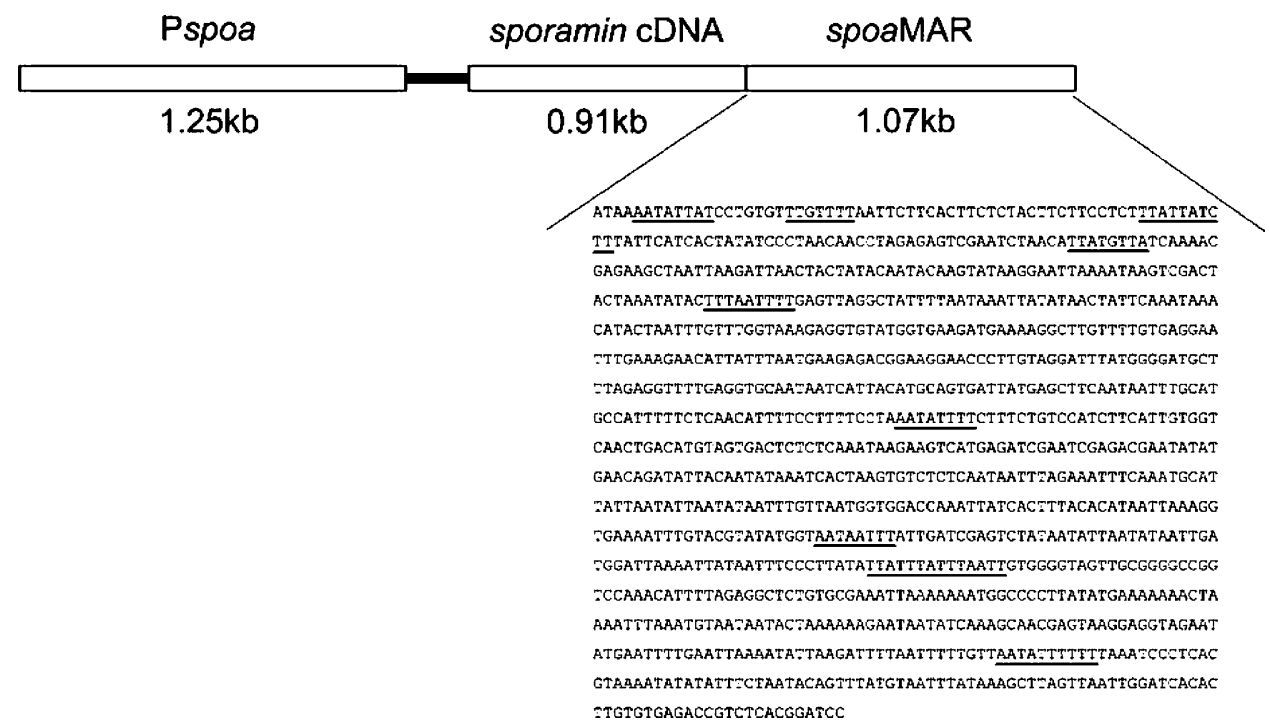

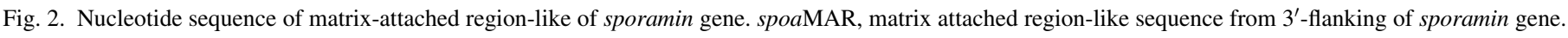
The nucleotide sequence of spoaMAR is characterized with some MAR motifs, such as TTTAATTT and AATATTTT etc. 
(a)

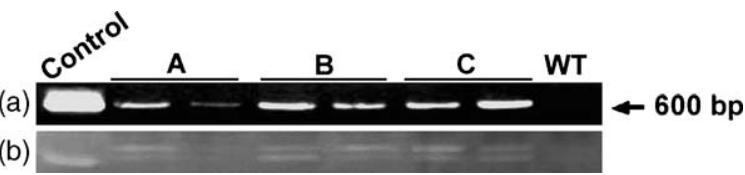

Fig. 3. RT-PCR analysis and gel staining of trypsin inhibitor (TI) activity to detect sporamin gene expression level in $\mathrm{T}_{0}$ transgenic Brassica and wild type plant. A indicated the two transgenic Brassica lines of pP35S-sporamin. B indicated the transgenic Brassica of pPspoa-sporamin. C was the transgenic Brassica lines of pPspoa-sporamin-spoaMAR. Wt, wild type Brassica. (a) Sporamin gene expressions detected by RT-PCR with sporamin gene specificprimers, and the PCR product size is $660 \mathrm{bp}$. Control for RT-PCR was using the plasmid containing the sporamin cDNA as the template of PCR. (b) TI activity analyzed by gel activity analysis. The sample for the control of TI activity assay was the protein of trypsin inhibitor extracted from soybean and the molecular weight was $20 \mathrm{kDa}$.

has an additional $1.1 \mathrm{~kb}$ flanking sequence attached to the downstream site of $3^{\prime}$-end of sporamin cDNA (Fig. 1). This flanking sequence was originally located at the $3^{\prime}$ downstream non-transcriptional region of sporamin genomic clone [18]. Nucleotide sequence analysis showed this DNA fragment was $\mathrm{A}-\mathrm{T}$ rich $(75 \% \mathrm{~A} / \mathrm{T} \mathrm{bp})$ and contained several conspicuous characters of matrix attached region (MAR) such as MAR box (5' AATATTTTT $3^{\prime}$ ) and T-box (5' TTA/TTA/TTTA/TTT $3^{\prime}$ ) (Fig. 2).

\subsection{Comparison of sporamin expression levels in transgenic Brassica plants harboring with different T-DNA constructs}

Three constructs were transformed to $B$. oleracea mediated Agrobacterium infection. An appropriate scale of $\mathrm{T}_{0}$ transgenic lines was regenerated and selected through kanamycin contained-medium. Forty independent lines of $\mathrm{T}_{0}$ transgenic plants of each T-DNA construct transformation were selected. RT-PCR analysis using sporamin gene-specific primers was employed to detect sporamin gene expression level in leaves of kanamycin-resistant transformants. As shown in Fig. 3a, most kanamycin-resistant $T_{0}$ transformants positively displayed a RT-PCR product of 660 bp DNA fragment. Furthermore, these selected transformants showed trypsin inhibitor activity of sporamin, and the activity level positively correlated to the RTPCR results (Fig. 3b). Difference in the levels of expression of sporamin gene was among these three construct transformants. In general, the transformants of gene constructs, pPspoa- sporamin and pPspoa-sporamin-spoaMAR, showed higher expression level than those of pP35S-sporamin constructs. Ten independent lines, randomly selected from $40 \mathrm{~T}_{0}$ transgenic plants of each T-DNA construct transformation, were assayed for TI activity level. It revealed that the transformants of pP35Ssporamin resulted in most of the individuals ( 7 out of 10 individuals) showing trypsin-inhibited efficiency lower than $50 \%$, and few individuals showing the inhibited efficiency higher than $70 \%$. The maximal activity was $95 \%$, whereas minimum inhibited efficiency was only $2 \%$ (Fig. 4a). It showed a marked bimodal expression pattern in pP35S-sporamin construct. On the other hand, 8 out of 10 transformants of both pPspoa-sporamin and pPspoa-sporamin-spoaMAR constructs showed the trypsin-inhibited efficiency higher than 50\%, respectively (Fig. $4 \mathrm{~b}$ and c). The average TI activity of $\mathrm{T}_{0}$ transformants of the each three constructs was $42 \%$ in pP35Ssporamin, 68\% in pPspoa-sporamin and $70 \%$ in pPspoasporamin-spoaMAR, respectively.

To further investigate the variability of the TI activity within individual $\mathrm{T}_{1}$ transformant at various organs, leaves, stems and flowers from three primary transformants of each T-DNA constructs were sampled at 45 day after germination (DAG). In all pP35S-sporamin transformants, young leaves (L1), uppersection stem (US) and flower tissue expressed high level TI activity, whereas TI activity was dropped to a very low level in mid-aged leaves (L4), aged leaves (L7) as well as in lowersection stem (LS) (Fig. 5). On the other hand, the transformants harboring the constructs with Pspoa retained almost consistent and high level of TI activity in whole plants (Fig. 5).

\subsection{Stable trypsin inhibitor expression in second- generation of the sporamin-transformants}

Based on $T_{1}$ segregation test (data not shown), three of the single-locus transformants of each T-DNA constructs were randomly selected to determined the stability of sporamin expression in second generation $\left(T_{1}\right)$. At least, 10 progeny plants from each parental line were further grown to study TI activity. TI activity in $\mathrm{T}_{1}$ population of all the three constructstrangenic plants is shown in Fig. 6. $\mathrm{T}_{1}$ population of pP35Ssporamin transformation showed high variation of TI activity, and the TI activity level of $\mathrm{T}_{1}$ generation deviated strongly from that of the parental plants (Fig. 6a). pPspoa-sporamin showed a moderately reducing TI activity compared to that of the
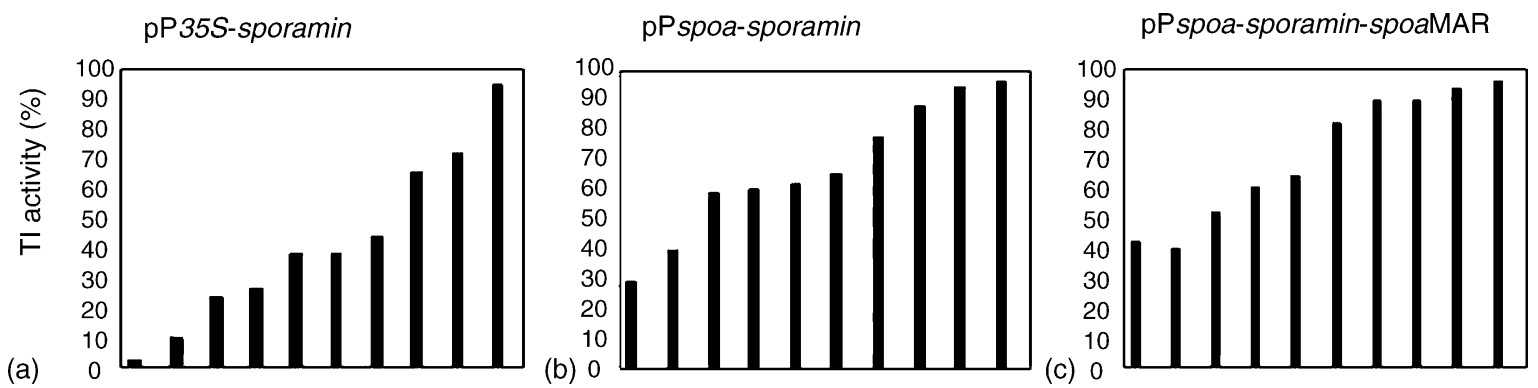

Fig. 4. Trypsin inhibitor (TI) activity of sporamin gene expressed in inhibitory percent (I \%) in $\mathrm{T}_{0}$ transgenic Brassica. The TI activity was presented as the percentage of trypsin activity was inhibited. Ten individual $\mathrm{T}_{0}$ plants were randomly selected to assay from each construct transformation. 


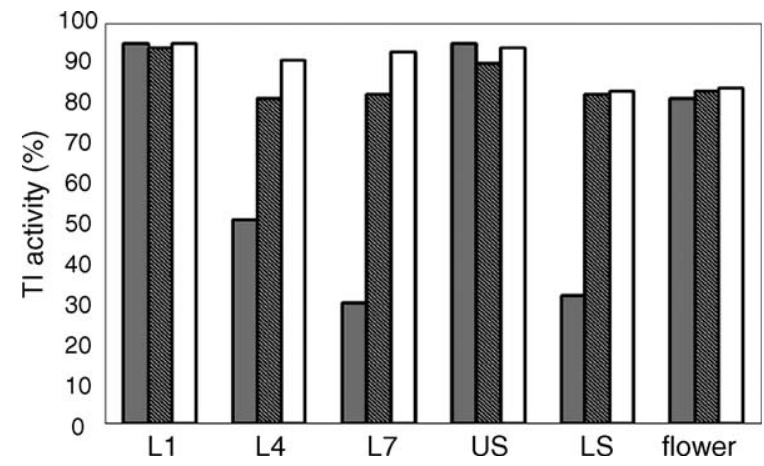

Fig. 5. Variation of trypsin inhibitor activity expressed in different tissues (leaf, stem, and flower) in $\mathrm{T}_{1}$ Brassica plants transformed with pP35S-sporamin, pPspoa-sporamin and pPspoa-sporamin-spoaMAR. Three replicates of individual transgenic Brassica of each T-DNA construct were used to assay TI activity. L1, L4 and L7 represent corresponding leaves located from apical bud; US and LS represent the upper portion and lower portion of stem. $\square$ represents pP35S-sporamin transformants; $\mathbb{N}$ represents pPspoa-sporamin transformants; $\square$ represents pPspoa-sporamin-spoaMAR transformaants.

parental plants (Fig. 6b). Trypsin inhibitor activity of $\mathrm{T}_{1}$ generation of pPspoa-sporamin-spoaMAR, however, showed highly stable expression levels (Fig. 6c).

Investigation on $\mathrm{T}_{2}$ Brassica grown on field, individuals of pP35S-sporamin transformation almost lost the TI activity (Fig. 7). However, individuals of the $\mathrm{T}_{2}$ transgenic population harboring the construct containing sporamin promoter retained TI activity expression and insect-resistance (Fig. 7).

\subsection{Comparison of resistance to $H$. armigera among transgenic plants harboring different constructs}

In order to understand the relationship between the TI activity expression level and the insect resistance in transgenic Brassica, the same size of transgenic leaves, detached from randomly selected $\mathrm{T}_{2}$ populations of each three T-DNA constructs and wild type plants, were put in petri dish to feed second instar larvae of $H$. armigera individually. As expected, the weight of twenty insects fed with the sporamin-transgenic Brassica has the lighter weight than that fed with wild type plants (Table 1), and the size of sporamin-transgenic plant fed larvae were generally smaller than that of controls (Table 1 and Fig. 8). Moreover, the average survival rates of the larva fed with pP35S-sporamin was 40\%; however, the survival rate of the larva fed with pPspoa-sporamin and pPspoa-sporamin-spoaMAR transgenic were only 16 and $4 \%$, respectively (Table 1 ). In addition, transgenic population of CaMV35S promoter construct showed marked variability in insect resistance (data not shown).

\section{Discussion}

Previously it has been shown that Pspoa promoter is highly activated in response to wounding [5]. The cis-acting elements on the Pspoa promoter region were completely characterized, and several regulatory elements responded to wounding and pathogenic stresses have been observed (unpublished data). In this study, the expression of TI activity in individual $\mathrm{T}_{0}$
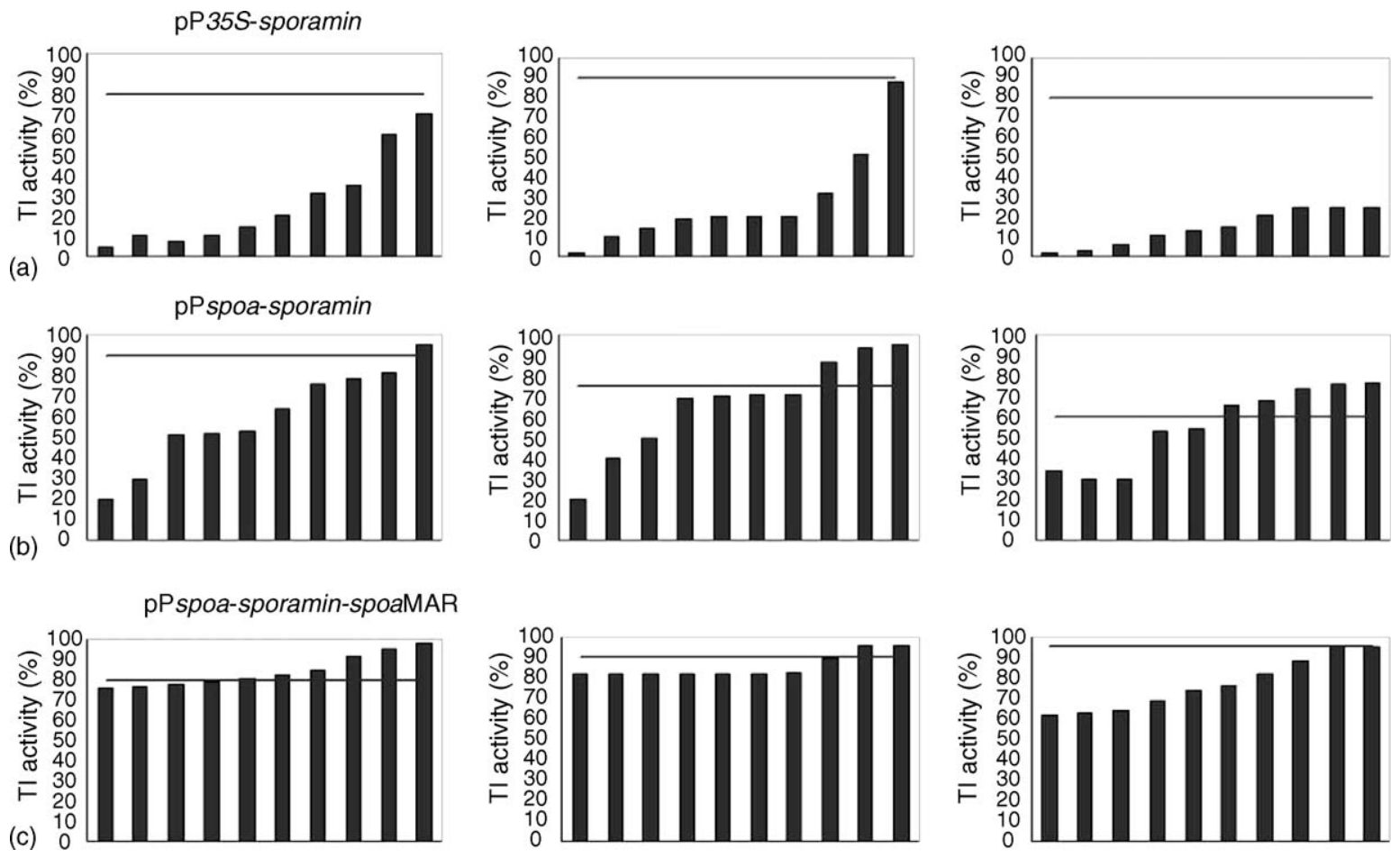

Fig. 6. Trypsin inhibitory activity of 10 transgenic progeny plants derived from each three single-locus $\mathrm{T}_{0}$ Brassica. TI activity of the parental plant (in $\mathrm{T}_{0}$ generation) is represented by a horizontal line in each figure. (a) TI activity of $\mathrm{T}_{1}$ generation of pP35S-sporamin transformants. (b) TI activity of $\mathrm{T}_{1}$ generation of pPspoasporamin transformants. (c) TI activity of $\mathrm{T}_{1}$ generation of pPspoa-sporamin-spoaMAR transformants. The three groups of independent data in each (a)-(c) indicated the results got from the secondary generation of three different $\mathrm{T}_{0}$ transgenic plants, respectively. 


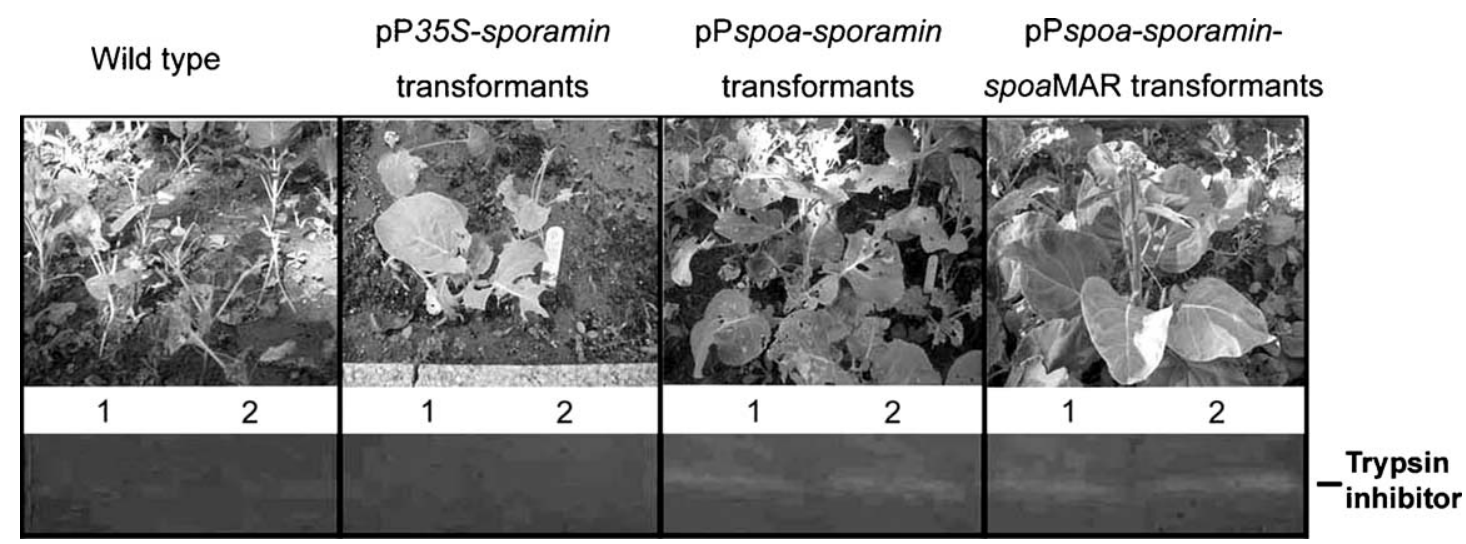

Fig. 7. Trypsin inhibitor activity of $\mathrm{T}_{2}$ Brassica plants transformed with $\mathrm{pP} 35$ S-sporamin, pPspoa-sporamin and pPspoa-sporamin-spoaMAR. Equal amount $(100 \mu \mathrm{g})$ of crude protein extract from young leaves was assayed on SDS-PAGE. Panel (a) shows the $\mathrm{T}_{2}$ and wild type Brassica plants growing in the trial field. Panel (b) shows the TI activity stain of crude leaf protein extracts on SDS-PAGE, which were represented by two selected independent lines.

Table 1

Results of maize cutworm (Helicoverpa armigera) biossays on $\mathrm{T}_{2}$ transformed plants

\begin{tabular}{lccc}
\hline Plants & $\begin{array}{l}{ }^{\mathrm{a}} \text { Number of sampled } \\
\text { transformants }\end{array}$ & $\begin{array}{l}\text { Average body weight of total } \\
\text { incubated insects } \pm \text { S.D. }(\mathrm{mg})\end{array}$ & $\begin{array}{l}\text { Insect survival } \\
\text { rate }(\%)\end{array}$ \\
\hline Wild type & 4 & $31.6 \pm 3.6$ & 100 \\
pP35S-sporamin & 10 & $22.5 \pm 2.1$ & 40 \\
pPspoa-sporamin & 10 & $10.3 \pm 1.5$ & 16 \\
pPspoa-sporamin spoaMAR & 10 & $6.2 \pm 1.81$ & 4 \\
\hline
\end{tabular}

\footnotetext{
${ }^{a}$ Number of sample plants used in the insect bioassay.
}

Brassica plant was not boosted by sporamin promoter. The average value of TI activity, however, is higher than those CaMV35S transformant population (Fig. 4). This is due to most of the transgenic Brassica harboring the Pspoa-sporamin and Pspoa-sporamin-spoaMAR expressed the high level sporamin and the prominent reduction in of inter-variability in these two transformant populations. The possible mechanism of the outcome is that sporamin promoter is an efficient inducible promoter [5], rather than a constitutive expression like CaMV35S promoter. Another advantage of Pspoa is that it can be induced to express systemically by wounding in short

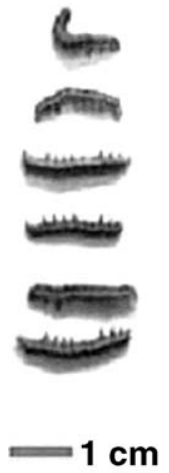

(A)

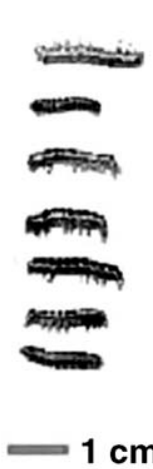

(B)

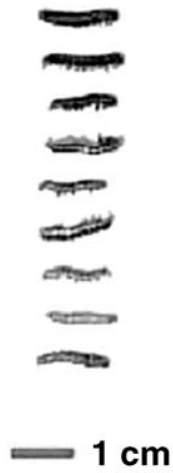

(C)

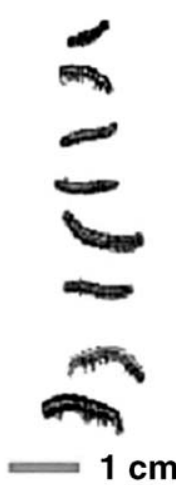

(D)
Fig. 8. Effect of sporamin on the maize cutworm fed with the sporamin transgenic Brassica. Maize cutworms (Helicoverpa armigera) were fed with leaves of wild type Brassica (A), pP35S-sporamin (B), pPspoa-sporamin (C) and pPspoa-sporamin-spoaMAR (D) transgenic Brassica for 4 days, respectively. term. This property of Pspoa promoter can be of significant importance for application in transgene-overexpressing plants. Based on the spatial analysis of TI activity in transgenic plants, high level of TI activity is systemically consistent in transformants containing the construct with sporamin promoter (Fig. 5). These results indicated that Pspoa promoter conferred the consistent systemic expression of sporamin throughout the whole plant, and Pspoa was more stable compared to CaMV35S promoter in transgene expression.

It would be advantageous that a transgenic plant keeps the characters including high-level transgene expression, low intertransformant variability and consistent inherent stability in subsequent generations. However, it is not easy to combine all these traits in a transgenic plant. For example, strong promoters such as $C a M V 35 S$ and cassava vein mosaic virus promoter are widely used and can lead to high transgene expression, but the expression is also more prone to gene silencing than the expression obtained by the weaker promoters $[23,24]$. Moreover, the strong promoters are always with the drawback of high inter-transformants variability. Our observation on the previous transgenic Tobacco and cauliflower overexpressed the sweet potato sporamin gene drove by CaMV35S promoter clearly displayed the situation, and it was not sufficient to guarantee stable expression in successive generation [7,8]. As shown in Fig. 6c and 7, sporamin promoter is generally better than CaMV35S promoter to maintain highly stable transgene expression in the subsequent generation of single-locus parental plants.

It has been shown that the $3^{\prime}$-flanking regions of some genes play a regulatory role in gene expression such as the $3^{\prime}$ region of 
Pvlea-18 gene encoding a member of late embryogenesisabundant (LEA) proteins in Phaseolus vulgaris has been proven to increase the gene expression level during growth and development, and response to dehydration [25]. The $3^{\prime}$-flanking sequence cloned from sporamin gene [26] showed the character of MAR sequence (motifs) (Fig. 2). To date, MAR effect on gene expression has been reported only in a few cases $[13,17,26,27]$, however, it is recognized generally as an efficient suppressor of inter-individual variation of transgene expression. The spoaMAR sequence appears to enhance the function of Pspoa promoter and stabilize the wound-inducible regulation of Pspoa promoter expression in transgenic plants (Fig. 4). Moreover, it is effective in retaining the stability of TI expression level in successive generation (Figs. 6c and 7). It is quite possible that this DNA region might have the potentiality to play a function like MAR in stabilizing transgene expression and reducing position-induced quantitative difference among independent transformants [28-30]. These results suggested that spoaMAR got potential for transgenic crop production.

In conclusion, since the TI activity and insect resistance was not stable enough in pP35S-sporamin transgenic plants, the combination of Pspoa and spoaMAR successfully improvement the efficiency and stability of both TI activity and insectresistance in transgenic Brassica. The Pspoa and spoaMAR on transgenic constructs reduced the variability of TI activity in inter-transgenic plants and inter-generation. These results suggested that the inducible sporamin promoter combined with MAR is an excellent strategy to express the insect-resistant protein, sporamin, in Brassica. Even the MAR function on transgene expression in crops has been reported, based on our knowledge, this is the first paper directly proved the MAR could apply to biotechnology for improving the physiological trait of crop such as insect-resistance.

\section{Acknowledgements}

We are grateful to Dr. S.H. Kao (Department of Biopesticide, Taiwan Agricultural Chemicals and Toxic Substance Research Institute, Taichung, Taiwan) for kindly providing the second instar maize cutworm larvae for insect bioassay on transgenic plants.

\section{References}

[1] M. Maeshima, T. Sasaki, T. Asahi, Characterization of major proteins in sweet potato tuberous roots, Phytochemistry 24 (1985) 1899-1902.

[2] T. Hattori, N. Yoshida, K. Nakamura, Structural relationship among the members of multigene family coding for the sweet potato tuberous roots storage proteins, Plant Mol. Biol. 13 (1989) 563-572.

[3] T. Hattori, S. Nakagawa, K. Nakamura, High-level expression of tuberous root storage protein genes of sweet potato in stem of plantlets grown in vitro on sucrose medium, Plant Mol. Biol. 14 (1990) 595-604.

[4] M. Ohto, K. Nakamura-Kito, K. Nakamura, Induction of expression of genes coding for sporamin and $\beta$-amylase by polygalacturonic acid in leaf-petiole cuttings of sweet potato, Plant Physiol. 99 (1992) 422-427.

[5] S.J. Wang, Y.C. Lan, S.F. Chen, Y.M. Chen, K.W. Yeh, Wound-response regulation of the sweet potato sporamin gene promoter region, Plant Mol Biol. 48 (2002) 223-231.
[6] K.W. Yeh, J.C. Chen, M.I. Lin, Y.M. Chen, C.Y. Lin, Functional activity of sporamin from sweet potato (Ipomoea batatas) - a tuberous storage protein with trypsin inhibitor activity, Plant Mol. Biol. 33 (1997) 565570

[7] K.W. Yeh, M.I. Lin, S.J. Tuan, Y.M. Chen, C.Y. Lin, S.S. Kao, Sweet potato (Ipomoea batatas) trypsin inhibitors expressed in transgenic tobacco plants confer resistance against Spodoptera litura, Plant Cell Rep. 16 (1997) 696-699.

[8] L.C. Ding, C.Y. Hu, K.W. Yeh, P.Y. Wang, Development of insect-resistant transgenic cauliflower plants expressing the trypsin inhibitor gene isolated from local sweet potato, Plant Cell Rep. 17 (1998) 854-860.

[9] D.G. Cai, T. Thurau, Y. Tian, T. Lange, K.W. Yeh, C. Jung, Sporaminmediated resistance to beet cyst nematode (Heterodera schachtii $\mathrm{Schm}$.) is dependent on trypsin inhibitory activity in sugar beet (Beta vulgaris L.) hairy root, Plant Mol. Biol. 51 (2003) 839-849.

[10] P. Meyer, Variation of transgene expression in plants, Euphytica 85 (1995) 359-366.

[11] P. Meyer, Transcriptional transgene silencing and chromatin components, Plant Mol. Biol. 43 (2000) 221-234.

[12] R.E. Down, L. Ford, S.J. Bedfod, L.N. Gatehouse, C. New, J.A. Gatehouse, A.M.R. Gatehouse, Influence of plant development and environment on transgene expression in potato and consequences for insect resistance, Transgenic Res. 10 (2002) 223-236.

[13] M.F.C. De Bolle, K.M.J. BUtaye, W.J.W. Coucke, I.J.W.M. Goderies, P.F.J. Wouters, N. Van Boxel, W.F. Broekaert, B.P.A. Cammue, Analysis of the influence of promoter elements and a matrix attachment region on the inter-individual variation of transgene expression in populations of Arabidopsis thaliana, Plant Sci. 165 (2003) 169-179.

[14] T. Elamayan, H. Vaucheret, Expression of single copies of a strongly expressed $35 \mathrm{~S}$ transgene can be silenced post-transcriptionly, Plant J. 9 (1996) 787-797.

[15] J. Bode, C. Benham, A. Knopp, C. Mielke, Transcriptional augmentation: modulation of gene expression by scaffold/matrix-attached regions (S/ MAR elements), Crit. Rev. Eukaryot. Gene Expr. 10 (2000) 73-90.

[16] R. Holmes-Davis, L. Comai, Nuclear matrix attachment regions and plant gene expression, Trends Plant Sci. 3 (1998) 157-162.

[17] G.C. Allen, S. Spiker, W.F. Thompson, Use of matrix attachment regions to minimize transgene silencing, Plant Mol. Biol. 43 (2000) 361-376.

[18] S.J. Wang, C.T. Lin, K.C. Ho, Y.M. Chen, K.W. Yeh, Nucleotide sequence of sporamin gene in sweet potato, Plant Physiol. 108 (1995) 829-830.

[19] R. Hofgen, L. Willmitzer, Storage of competent cells for Agrobacterium transformation, Nucleic Acids Res. 16 (1988) 9877.

[20] G.B. Poulsen, Genetic transformation of Brassica, Plant Breeding 115 (1996) 225-251.

[21] M.M. Bradford, A rapid and sensitive method for the quantization of microgram quantities of protein utilizing the principle of protein-dye binding, Anal. Biochem. 72 (1976) 248-254.

[22] P.E. Yao, M.J. Hwang, Y.M. Chen, K.W. Yeh, Site-directed mutagenesis evidence for a negatively charged trypsin inhibitory loop in sweet potato sporamin, FEBS Lett. 24841 (2001) 1-5.

[23] Q. Que, H.Y. Wang, J.J. English, R.A. Jorgensen, The frequency and degree of cosuppression by sense chalcone synthase transgenes are dependent on transgene promoter strength and are reduced by premature nonsense codons in the transgene coding sequence, Plant Cell 9 (1997) 1357-1368.

[24] K.M.J. Butaye, I.J.W.M. Goderis, P.F.J. Wouters, J.M.T.G. Pues, S.L. Delaure, W.F. Broekaert, A. Depicker, B.P.A. Cammue, M.F.C. Bolle, Stable high-level transgene expression in Arabidopsis thaliana using gene silencing mutants and matrix attachment regions, Plant J. 39 (2004) 440449.

[25] L.P. Moreno-Fonseca, A.A. Covarrubias, Downstream DNA sequences are required to modulate $P$ vlea-18 gene expression in response to dehydration, Plant Mol. Biol. 45 (2001) 501-515.

[26] S.J. Oh, J.S. Jeong, E.H. Kim, N.R. Yi, S.I. Yi, I.C. Jang, Y.S. Kim, S.C. Suh, B.H. Nahm, J.K. Kim, Matrix attachment region from the chicken lysozyme locus reduces variability in transgene expression and confers copy number-dependence in transgenic rice plants, Plant Cell Rep. 24 (2005) 145-154. 
[27] H. Xue, Y.T. Yang, C.A. Wu, G.D. Yang, M.M. Zhang, C.C. Zheng, TM2, a novel strong matrix attachment region isolated from tobacco, increases transgene expression in transgenic rice calli and plants, Theor. Appl. Genet. 110 (2005) 620-627.

[28] A. Stief, W.H. Winter, W.H. Straetling, A.E. Sippel, A nuclear DNA attachment element mediates elevated and position-independent gene activity, Nature 341 (1989) 343-345.
[29] P. Breyne, M. Van Montague, A. Depicker, G. Gheysen, Characterization of a plant scaffold attachment region in a DNA fragment that normalizes transgene expression in tobacco, Plant Cell 4 (1992) 463-471.

[30] W. Van Leeuwen, L. Mlynarova, J.P. Nap, L.H.W. van de Plas, A.R. van der Krol, The effect of MAR elements on variation in spatial and temporal regulation of transgene expression, Plant Mol. Biol. 47 (2001) 543-554. 